\title{
Study of surgical management of fracture of proximal humerus by PHILOS plate and screws
}

\section{Channappa T. Seetharam*, Manju Jayaram, Shivakumar H. Bachhappa, Yatish Ramalingaiah, Syed Abdul Hadi}

Department of Orthopaedics, Kempegowda Institute of Medical Sciences, V V Puram, Bangalore, Karnataka, India

Received: 01 February 2020

Revised: 24 March 2020

Accepted: 31 March 2020

\section{*Correspondence:}

Dr. Channappa T. Seetharam,

E-mail: drchannappa@yahoo.co.in

Copyright: (c) the author(s), publisher and licensee Medip Academy. This is an open-access article distributed under the terms of the Creative Commons Attribution Non-Commercial License, which permits unrestricted non-commercial use, distribution, and reproduction in any medium, provided the original work is properly cited.

\section{ABSTRACT}

Background: Proximal humerus fracture accounts for about 5\% of all fractures in recent advances proximal humerus fractures are often managed operatively with PHILOS plate which provides greater angular stability and study was aimed at to assess functional outcome of PHILOS plate fixation in proximal humerus fractures.

Methods: Prospective study of 31 cases of proximal humerus fractures admitted and operated in Kempegowda Institute of Medical Sciences Hospital November 2017 to May 2019 of which 4 patients died due to medical comorbidities so 27 patients were studied. Follow-up of these patients was done at 6 weeks, 12 weeks and 24 weeks with functional evaluation was done using Constant and Murley (CM) scoring and disabilities of the arm, shoulder and hand (DASH) scoring.

Results: CM scoring and DASH scoring was applied to analyze the functional outcome among the cases. Most of the patients had excellent outcome $(52 \%)$ followed by good $(26 \%)$, fair $(8 \%)$ and poor $(15 \%)$ outcome according to CM scoring and according to DASH scoring 20.21 was mean score and mean CM score was 77.62. Complications observed were impingement in 1 patient, avascular necrosis in 2 patient and non union in 1 case.

Conclusions: We conclude that the use of PHILOS plate for the fixation of proximal humerus fractures is a good device as it provides rigid fixation and early mobilisation and prevented complications. Precontoured locking plates work on the principle of angular stability, divergent screws, less disruption of vascularity and less chances of plate failure.

Keywords: Proximal humerus, PHILOS plate, Constant and Murley score, DASH score

\section{INTRODUCTION}

Proximal humerus fractures accounts for approximately 4$5 \%$ of all the fractures and are next to hip fractures and distal radius fractures in the elderly population. ${ }^{1}$ The majority of patients are elderly, which is due to the risk for their bones to be osteoporotic or brittle. The bone quality seems to be crucial both for the surgical intervention and the functional outcome. Most patients about $80 \%$ with undisplaced proximal humerus fractures can be treated conservatively with good functional outcome. Surgery should be considered in about $20 \%$ of patients. ${ }^{1-3}$ Many different techniques have been described for treatment of proximal humerus fractures such as transosseous suture fixation, tension band wiring, standard plate and screw fixation, hemireplacement arthroplasty, percutaneous wire, and screw fixation. ${ }^{4}$ Precontoured locking plates work on the principle of angular stability, divergent screws, less disruption of vascularity and less chances of plate failure. Locking plate modality is the gold-standard modality in the treatment of proximal humerus fractures and is chiefly used to overcome certain issues like 
metaphyseal comminution and have reduced the incidence of thesecomplications. ${ }^{5,6}$

Complications associated with the PHILOS plate fixation include screw penetration into the glenohumeral joint, screw loosening and back out, avascular necrosis of the humeral head, pseudoarthrosis with a broken plate, subacromial impingement requiring plate removal, nonunion, malunion due to loss of purchase in the humeral head, broken distal screws with separation of the plate from the bone, and transient axillary nerve palsies. ${ }^{7}$

In proximal humerus fractures, PHILOS plate offers a good functional outcome with context to the early joint mobilisation and rigid fixation of the fracture. ${ }^{8}$ The locking plate can be used with a minimally invasive technique which permits indirect fracture reduction thus lowering the possibility of avascular necrosis (AVN) and also lowering of time of immobilization reduces the possibility of frozen shoulder. 9,10 Furthermore, the proximal locking screw having the capability of being applied in multidirections makes it a fixating device with a high stability in osteoporotic bones. ${ }^{11}$ Considering these advantages and the scarcity of data on the efficacy and the functional outcome following internal fixation with PHILOS plate for displaced proximal humerus fractures, the present study was planned.

\section{METHODS}

This prospective study was conducted at Kempegowda Institute of Medical Sciences, Bangalore from November 2017 to May 2019. A total of 31 cases sustained proximal humerus fracture and were operated with open reduction and internal fixation with PHILOS plate and screws of which 4 patients died due to medical comorbidities during post op period and total of 27 patients were studied. Follow up of these patients were done at 6 weeks, 12 weeks and 24 weeks after surgery and functional outcome was evaluated using Constant and Murley (CM) scoring and disabilities of the arm, shoulder and hand (DASH) scoring.

\section{Inclusion criteria}

All skeletally mature patients more than 18 years, simple fractures, displaced proximal humerus fractures, NEER two,three and four part fracture were included. ${ }^{12}$

\section{Exclusion criteria}

Pathological fractures, failure of conservative treatment, any associated fractures in ipsilateral limb were excluded.

\section{Evaluation of patients}

The local examination of injured shoulder was done to look for the attitude, swelling, deformity and loss of function. Any nerve injury was also carefully looked for and noted by regimant batch sign. Local neurological deficit of axillary nerve over lateral aspect of shoulder was assessed by looking for anaesthetic patch. Fracture was stabilized temporarily by shoulder immobiliser. A thorough preoperative assessment of the patients was done, which included general condition of the patient and clinical (inspection, palpation, measurements, movements, associated injuries) and radiological assessment of the type of the fracture.

Patients were evaluated for associated medical problems and reference was taken from respective departments and necessary treatment started and fitness for surgery taken.

Brachial block or general anaesthesia was used in all the patients according to their medical condition.

Patients placed in supine position on operating table with a small pillow at interscapular area. Drape the arm free, because it will have to be moved during the approach.

\section{Operative technique}

The surgical approach preferred was Deltopectoral approach. Through delto-pectoral approach, the fracture site was exposed and reduced with minimal soft tissue dissection. Briefly, the anatomical relationship between humeral head and greater tuberosity was reduced and fixed temporarily with $\mathrm{K}$ wires. In case of obvious rotation or displacement of the humeral head, a joystick technique was used. Then the shaft fragment was reduced by abduction, traction and rotation of the arm. When acceptable reduction is obtained, the PHILOS plate will be placed atleast $1 \mathrm{~cm}$ distal to the upper end of the greater tuberosity and fixed to the humeral shaft. All proximal locking screws were placed in a unicortical fashion through an external guide and confirmed to be within the humeral head with intraoperative fluoroscopy. AP (internal and external rotation) views and axillary views 90 degrees to each other were used to visualize screw placement. The distal shaft screws were placed bicortically. A minimum of three bicortical screws were used. Fluoroscopic images were taken to confirm satisfactory fracture reduction, plate positioning and proper length of screws in the humeral head. Range of motion of shoulder was checked on the table for impingement. Wound was closed in layers and sterile dressing was done.

\section{Post operative management}

After surgery the shoulder was immobilised in a universal shoulder immobiliser. Appropriate antibiotics as well as analgesics were used. Post operative check radiographs were taken to determine the alignment of the bne and maintenance of reduction. Sutures removed by $12^{\text {th }}$ day. The passive pendulum exercises are begun as soon as possible. At first week passive range of motion started. Active range of motion was started at 2 to 4 weeks postoperatively, depending on stability of osteosynthesis. 


\section{Follow up}

Follow-up of patients was done at six weeks, three months and six months following the surgery. radiographs were performed at the end of six weeks, three months and six months follow-up. Patients were evaluated based on the following parameters at the time of discharge and all the three follow up for range of motion of the shoulder, complications, clinical union, radiological union.

\section{Functional outcome}

Final outcome was evaluated by constant shoulder score and DASH scoring.

CM score was conceived as a system of assessing the overall value, or functional state, of a normal, a diseased or a treated shoulder. ${ }^{13}$ In this score, 35 points are allocated for subjective assessments of pain and activities of daily living and 65 points are available for objective measures of range of movement and shoulder strength. A young healthy patient can therefore have a maximum score of 100 points. The final assessment using Constant shoulder score for outcome was interpreted as excellent- 86 to 100 points, good- 71 to 85 points, fair- 56 to 70 points and poor- 0 to 55 points.

DASH scoring is a non-shoulder specific scoring system and is mainly used to assess the symptoms and physical disability in the arm. It is a30-item patient-reported tool which is based on the symptoms, physical, social and psychological functions. It also evaluates the sleep disturbances. Greater the score represents greater disability and lower scores represents good functional outcome.

Data was entered in MS-excel 2007 and data was analysed using SPSS software version 22. Results were displayed in numbers; percentages only. $\mathrm{P}$ value less than 0.05 was considered statistically significant.

\section{RESULTS}

Majority of the patients $(65 \%)$ were males and male to female ratio was 1.8:1. Most of the patients presented with age from 51 to 60 years and mean age was $49.90 \pm 15.01$ years.

Road traffic accident was the nature of trauma in $55 \%$ of the patients and $42 \%$ had fall and $3 \%$ seizures. $52 \%$ of the patients presented with right sided proximal humerus fracture. Neer's classification was used to classify fractures and presented with 15 cases of 2-part fracture (50\%), 13 cases of $(42 \%) 3$ part and 3 cases of 4 part fracture $(10 \%)$. Most of the patients had surgery under general anaesthesia $(60 \%)$.

At first follow up at six weeks, pain at fracture site was noted in all the patients $(100 \%)$ and radiological union in (5\%). During second follow up at three months, radiological union in $88 \%$. Pain at fracture site was reported by $20 \%$ of the patients During third follow up at six months all the patients $(96 \%)$ had clinical and radiological union. The range of motion at first, second and third follow ups increased gradually during subsequent follow ups.

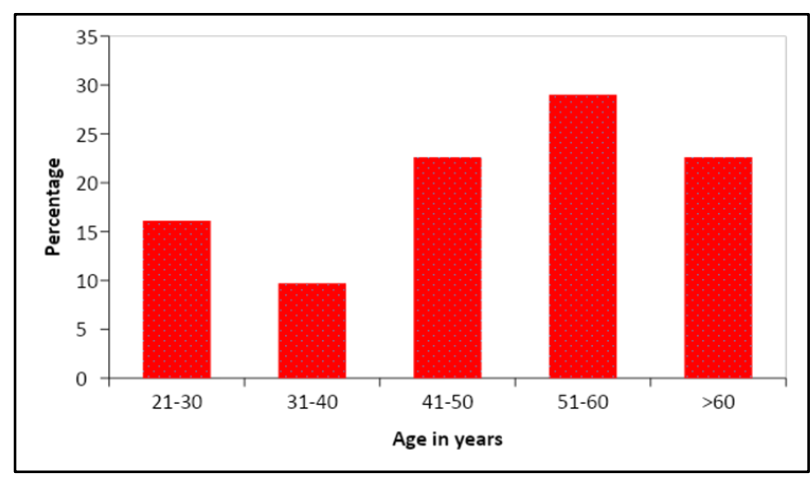

Figure 1: Age distribution of patients.

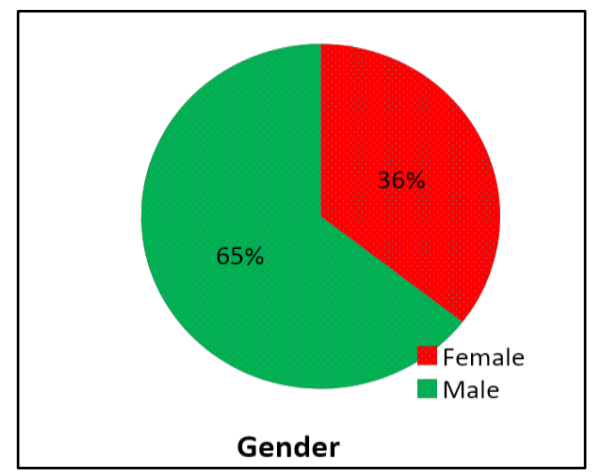

Figure 2: Gender distribution of patients.

Table 1: Patient outcome as per constant score.

\begin{tabular}{|llll|}
\hline Outcome & $\begin{array}{l}\text { CM } \\
\text { score }\end{array}$ & $\begin{array}{l}\text { No. of } \\
\text { patients }\end{array}$ & $\%$ \\
\hline Excellent & $86-100$ & 14 & 52 \\
\hline Good & $71-85$ & 7 & 26 \\
\hline Fair & $56-70$ & 2 & 7 \\
\hline Poor & $0-55$ & 4 & 15 \\
\hline Total & - & 27 & 100.0 \\
\hline
\end{tabular}

Table 2: DASH score distribution of patients studied.

\begin{tabular}{|llll|}
\hline Outcome & $\begin{array}{l}\text { DASH } \\
\text { score }\end{array}$ & $\begin{array}{l}\text { No. of } \\
\text { patients }\end{array}$ & $\%$ \\
\hline Excellent & $<20$ & 21 & 77.8 \\
\hline Good & $20-40$ & 2 & 7.4 \\
\hline Fair & $40-60$ & - & - \\
\hline Poor & $>60$ & 4 & 14.8 \\
\hline Total & - & 27 & 100.0 \\
\hline
\end{tabular}

Most of the patients had excellent outcome (52\%) followed by good $(26 \%)$, fair $(8 \%)$ and poor $(15 \%)$ outcome according to $\mathrm{CM}$ scoring and according to DASH 
scoring 20.21 was mean score and mean CM score was 77.62. No statistically significant difference was observed in outcome with regard to mechanism of injury $(p=0.291)$, side of the fracture $(\mathrm{p}=0.865)$ and type of fracture $(\mathrm{p}=0.131)$.

Table 3: Complications distribution of patients studied $(n=27)$.

\begin{tabular}{|lll|}
\hline Complications & No. of patients & $\%$ \\
\hline Nil & 23 & 85.2 \\
\hline Yes & 4 & 14.8 \\
\hline AVN & 2 & 8 \\
\hline Impingement & 1 & 4 \\
\hline Non union & 1 & 4 \\
\hline
\end{tabular}

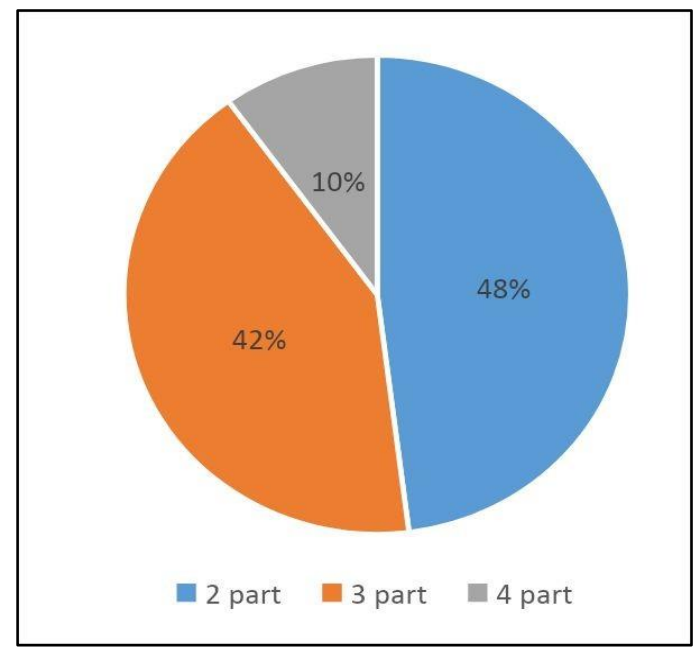

Figure 3: Pattern distribution of patients.

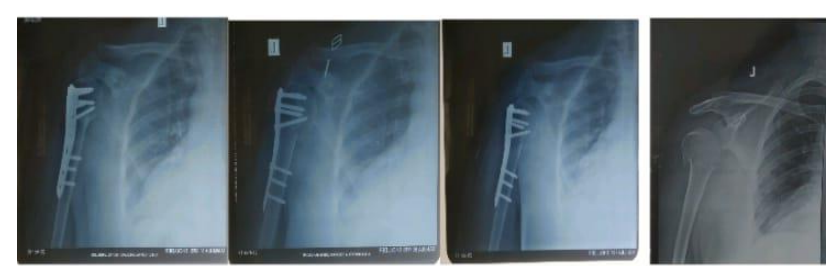

Figure 4: Case with excellent outcome.

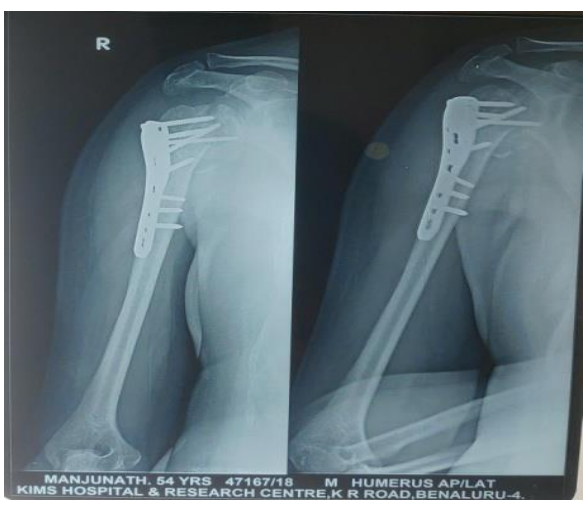

Figure 5: Case with poor outcome complication-non union.
Complications observed were sub acromial impingement $(4 \%)$, avascular necrosis $(8 \%)$ and non union $(4 \%)$. In the study conducted a total of $78 \%$ of patients had excellent and good outcome.

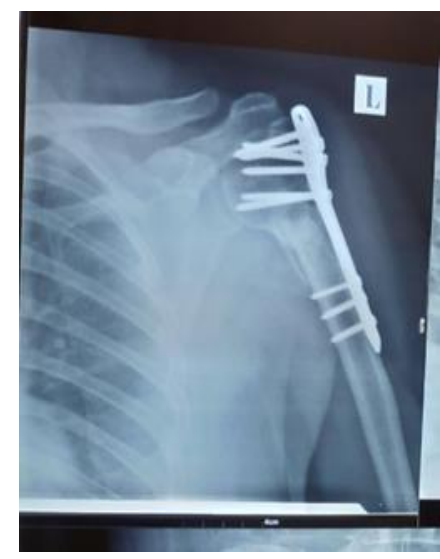

Figure 6: Case with poor outcome complicationsubacromial impingement.

\section{DISCUSSION}

Majority of displaced proximal humerus fractures treated with conventional plate and screws were associated with high rates of unsatisfactory outcome and complications. ${ }^{5}$ Locking plates provide angular stability of the screws and divergent and convergent nature of the screws which prevent implant backout in osteoporotic bones and calcar screws which prevent varus malalignent. ${ }^{10,11}$ Locking plate modality is the gold-standard modality in the treatment of proximal humerus fractures and is chiefly used to overcome certain issues like metaphyseal comminution. ${ }^{10}$ In this study 51t o 60 years was the commonest age group comprised of $30 \%$ of the patients. The mean age was found to be $49.9 \pm 15.01$ years and the younger patient was aged 21 years and the eldest was aged 78 years. These findings were consistent with a study by Gerber et al who reported mean age of 49.9 years. ${ }^{14}$ In the present study majority that is $65 \%$ of the patients were males with male to female ratio of 1.8:1 suggesting male preponderance which is in accordance with study of, Agarwal et al and Gerber et al reported male preponderance with male to female ratio of 1.7:1 and 1.35:1. ${ }^{14,15}$ The higher male to female ratio can be explained by the involvement of day to day activities of males compared to females. In the present study $55 \%$ of patients had history of RTA and $42 \%$ had history of fall and $3 \%$ with seizures. These findings were consistent with a study done by Josetm et al who reported RTA in 53\% of the patients and fall in $40 \%$ and seizures in $6 \%$. In this present study most of the patients presented with right fracture $(60 \%) .{ }^{16}$ Similar fracture pattern was reported in a study by Gracitelli et al. ${ }^{17}$ In this study 2-part fractures were noted in most of the cases $(48 \%)$ followed by 3 -part (42\%) and 4-part (10\%). Similar to the study conducted by Gracitelli et al. ${ }^{17}$ Majority of patients had union at 12 weeks about $92 \%$ and about $4 \%$ had union at 14 weeks and $4 \%$ had nonunion and fracture united with an average of 
12.08 weeks which is similar to the study of Egol et al. ${ }^{18}$ In this present study patients were evaluated also using CM and DASH scoring in which mean constant score was found to be 77.62 with $78 \%$ of patients having excellent and good outcome and mean DASH score was 20.21 In this present study 4 complications were observed in 27 patients that is $8 \%$ of patients had avascular necrosis of head of humerus, $4 \%$ of patients had sub acromial impingement and $4 \%$ had nonunion similar results were shown by Moonat et al. ${ }^{19}$

\section{CONCLUSION}

Proximal humerus internal locking system is a good device to stabilise proximal humerus fractures. The locking divergent screws prevent implant pullout and failure in fixation in osteoporotic fractures and the use of calcar screws prevent varus malaligment and loss of reduction by providing inferomedial support. The plate provides stable internal fixation and early mobilisation and anatomic reconstruction of tuberosities should be achieved for good functional outcome. The locking plate provides biological fixation as the periosteum and blood supply to fractured fragment is not compressed. Adequate stable fixation and appropriate physiotherapy exercises have a major role in functional outcome.

Funding: No funding sources

Conflict of interest: None declared

Ethical approval: The study was approved by the institutional ethics committee

\section{REFERENCES}

1. Court-Brown C, Garg A, McQueen M. The epidemiology of proximal humeral fractures. Acta Orthop Scand. 2001;72(4):365-71.

2. Handoll H, Gibson J, Madhok R. Interventions for treating proximal humeral fractures in adults. Cochrane Database Syst Rev. 2003(4):CD000434.

3. Court-Brown C, Caesar B. Epidemiology of adult fractures: A review. Injury. 2006;37(8):691-7.

4. Kumar C, Gupta AK, Nath R, Ahmad J. Open reduction and locking plate fixation of displaced proximal humerus fractures. Indian $\mathbf{J}$ Orthop. 2013;47(2):156-60.

5. Lanting B, MacDermid J, Drosdowech D, Faber K. Proximal humeral fractures: a systematic review of treatment modalities. J Shoulder Elbow Surg. 2008;17(1):42-54.

6. Murray IR, Amin AK, White TO, Robinson CM. Proximal humeral fractures: current concepts in classification, treatment and outcomes. J Bone Joint Surg Br. 2011;93(1):1-11.
7. Martinez AA, Cuenca J, Herrera A. Philos plate fixation for proximal humeral fractures. J Orthop Surg (Hong Kong). 2009;17(1):10-4.

8. Helmy N, Hintermann B. New trends in the treatment of proximal humerus fractures. Clin Orthop Relat Res. 2006;442:100- 8.

9. Kiliç B, Uysal M, Cinar BM, Ozkoç G, Demirörs H, Akpinar S. Early results of treatment of proximal humerus fractures with the PHILOS locking plate. Acta Orthop Traumatol Turc. 2008;42(3):149-53.

10. Bjorkenheim JM, Pajarinen J, Savolainen V. Internal fixation of proximal humeral fractures with alocking compression plate: are trospective evaluation of 72 patients followed for aminimum of 1 year. Acta Orthop Scand. 2004;75:741-5.

11. Koukakis A, Apostolou CD, Taneja T, Korres DS, Amini A. Fixation of proximal humerus fractures using the PHILOS plate: early experience. Clin Orthop Relat Res. 2006;442:115-20.

12. Neer CS. Displaced proximal humeral fractures.I: classification and evaluation. J Bone Joint Surg Am. 1970;52:1077-89.

13. Constant CR, Gerber C, Emery RJ, Søjbjerg JO, Gohlke F, Boileau P. Are view of the Constant score: modifications and guidelines for its use. J Shoulder Elbow Surg. 2008;17(2):355-61.

14. Gerber C, Schneeberger AG, Vinh TS. The arterial vascularization of the humeral head. J Bone Joint Surg. 1990;72:1486-93.

15. Aggarwal S, Bali K, Dhillon MS, Kumar V, Mootha AK. Displaced proximal humeral fractures: an Indian experience with locking plate. J Orthop Surg Res. 2010;5:60.

16. Jose TM, Vincent TA and George Paul A. Evaluation of the Outcome of Proximal Humerus Fracture Managed By Internal Locking Plate- A Prospective Study. IOSR J Dent Med Sci. 2017;16(5):36-43.

17. Gracitelli MEC, Lobo FL, Ferreira GMA, da Palma MV, Malavolta EA, Benegas E, et al. Outcomes evaluation of locking plate osteosynthesis in displaced fractures of the proximal humerus. Rev Bras Ortop. 2013;48(6):491-9.

18. Egol KA, Ong CC, Walsh M, Jazrawi LM, Tejwani NC, Zuckerman JD. Early complication of proximal humerus fractures treated with locked plates. J Orthop Trauma. 2008;22:159-64.

19. Moonot P, Ashwood N, Hamlet M. Early results for treatment of three- and four-part fractures of the proximal humerus using the PHILOS plate system. J Bone Joint Surg Br. 2007;89(9):1206-9.

Cite this article as: Seetharam CT, Jayaram M, Bachhappa SH, Ramalingaiah Y, Hadi SA. Study of surgical management of fracture of proximal humerus by PHILOS plate and screws. Int J Res Orthop 2020;6:462-6. 